\title{
Degradability, cytocompatibility, and osteogenesis of porous scaffolds of nanobredigite and PCL-PEG-PCL composite
}

This article was published in the following Dove Press journal:

International Journal of Nanomedicine

28 July 2016

Number of times this article has been viewed

\author{
Jun Hou' \\ Donghui Fan ${ }^{2}$ \\ Lingming Zhao ${ }^{2}$ \\ Baoqin $\mathrm{Yu}^{3}$ \\ Jiacan $\mathrm{Su}^{3}$ \\ Jie $\mathrm{Wei}^{2}$ \\ Jung-Woog Shin ${ }^{4}$ \\ 'The First Affiliated Hospital of Anhui \\ Medical University, Department \\ of Oral and Maxillofacial Surgery, \\ Hefei, ${ }^{2}$ Key Laboratory for Ultrafine \\ Materials of Ministry of Education \\ and The State Key Laboratory \\ of Bioreactor Engineering, East \\ China University of Science and \\ Technology, Shanghai, ${ }^{3}$ Department \\ of Orthopaedics Trauma, Changhai \\ Hospital, Second Military Medical \\ University, Shanghai, People's Republic \\ of China; ${ }^{4}$ Department of Biomedical \\ Engineering, Inje University, Gimhae, \\ Republic of Korea
}

Correspondence: Donghui Fan Key Laboratory for Ultrafine Materials of Ministry of Education, East China University of Science and Technology, Shanghai 200237, People's Republic of China

Email dyt90I208@I63.com

Jiacan Su

Department of Orthopedics Trauma, Changhai Hospital, Second Military Medical University, Shanghai 200433, People's Republic of China

Tel +862181873400

Fax +86 21 81873398

Email jiacansu@sina.com

\begin{abstract}
Biocomposite scaffolds were fabricated by incorporation of nanobredigite (n-BD) into the polymer of poly( $\varepsilon$-caprolactone)-poly(ethyleneglycol)-poly( $\varepsilon$-caprolactone) (PCLPEG-PCL). The results revealed that the addition of n-BD into PCL-PEG-PCL significantly improved water absorption, compressive strength, and degradability of the scaffolds of n-BD/ PCL-PEG-PCL composite (n-BPC) compared with PCL-PEG-PCL scaffolds alone. In addition, the proliferation and alkaline phosphatase activity of MG63 cells cultured on n-BPC scaffolds were obviously higher than that cultured on PCL-PEG-PCL scaffolds. Moreover, the results of the histological evaluation from the animal model revealed that the n-BPC scaffolds significantly improved new bone formation compared with the PCL-PEG-PCL scaffolds, indicating good osteogenesis. The n-BPC scaffolds with good biocompatibility could stimulate cell proliferation, differentiation, and bone tissue regeneration and would be an excellent candidate for bone defect repair.
\end{abstract}

Keywords: nanobredigite, PCL-PEG-PCL, biocomposite scaffolds, degradability, osteogenesis

\section{Introduction}

In the human body, magnesium $(\mathrm{Mg})$ is one of the most important elements that indirectly influences mineral metabolism and is closely associated with mineralization of calcined tissues. ${ }^{1,2}$ Some studies have shown that bioactive materials containing calcium (Ca), silicon ( $\mathrm{Si}$ ), and $\mathrm{Mg}$, such as bioglass, Si- or Mg-doped calcium-phosphate biomedical materials, etc, could induce the formation of biological apatite on their surfaces both in vitro and in vivo. ${ }^{3}$ These studies have shown that $\mathrm{Ca}, \mathrm{Si}$, and $\mathrm{Mg}$ ions could activate osteoblast proliferation and differentiation, stimulate bone-related gene expression, and facilitate new bone formation. ${ }^{4,5}$

Bredigite $\left(\mathrm{Ca}_{7} \mathrm{MgSi}_{4} \mathrm{O}_{16}\right)$, a Ca-, $\mathrm{Si}$-, and $\mathrm{Mg}$-containing bioceramic, was reported to possess good biocompatibility and was able to closely bond to bone tissue after implantation into bone defects of the rabbits. ${ }^{6,7}$ In addition, bredigite and its coating could promote the formation of bone-like apatite on material surface after soaking into stimulated body fluid. ${ }^{8}$ Moreover, the osteoblasts could adhere and spread well on the surfaces of bredigite bioceramics, and the ionic product dissolution from bredigite obviously stimulated cell proliferation. ${ }^{9,10}$ Therefore, bredigite-based biomaterials might open new possibilities for bone repair.

Degradable polymers of poly( $\varepsilon$-caprolactone)-poly(ethyleneglycol)-poly ( $\varepsilon$-caprolactone) (PCL-PEG-PCL) have been reported to possess good biocompatibility, 
and PCL-PEG-PCL has been applied as the nanoparticle for drug delivery or thermosensitive hydrogel. ${ }^{11,12}$ Biodegradable polymers with reasonable mechanical properties have been extensively applied to prepare the porosity scaffolds for bone regeneration owing to their biocompatibility and flexible nature. However, as for bone regeneration biomaterials, these polymers have some drawbacks, such as lack of bioactivity and low osteogenesis in vivo.

Biocomposites containing bioactive materials (such as calcium phosphate, silicate, and bioglass) and biodegradable polymers were extensively investigated, as these combined the advantages of both organic polymer and inorganic materials. ${ }^{13,14}$ It can be expected that the biological properties of bioactive composite would be improved if nanobredigite (n-BD) was incorporated into PCL-PEG-PCL. Therefore,

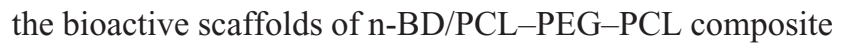
(n-BPC) were fabricated in this study, and the degradability, biocompatibility, and osteogenesis of the scaffold were also studied.

\section{Materials and methods}

\section{Synthesis of $n-B D$ and PCL-PEG-PCL}

n-BD $\left(\mathrm{Ca}_{7} \mathrm{MgSi}_{4} \mathrm{O}_{16}\right)$ was synthesized using calcium nitrate tetrahydrate $\left(\mathrm{Ca}\left(\mathrm{NO}_{3}\right)_{2} \cdot 4 \mathrm{H}_{2} \mathrm{O}\right)$, tetraethyl orthosilicate $\left(\left(\mathrm{C}_{2} \mathrm{H}_{5} \mathrm{O}\right)_{4} \mathrm{Si}, \mathrm{TEOS}\right)$, and magnesium nitrate hexahydrate $\left(\mathrm{Mg}\left(\mathrm{NO}_{3}\right)_{2} \cdot 6 \mathrm{H}_{2} \mathrm{O}\right)$ as raw materials. TEOS and $2 \mathrm{M}$ $\mathrm{HNO}_{3}$ were added into water (molar ratio: TEOS/ $\mathrm{HNO}_{3}$ / $\left.\mathrm{H}_{2} \mathrm{O}=1: 0.16: 8\right)$ and hydrolyzed with stirring for 40 minutes. After that, $\mathrm{Mg}\left(\mathrm{NO}_{3}\right)_{2} \cdot 6 \mathrm{H}_{2} \mathrm{O}$ and $\mathrm{Ca}\left(\mathrm{NO}_{3}\right)_{2} \cdot 4 \mathrm{H}_{2} \mathrm{O}$ were added into the mixed solution (molar ratio: $\mathrm{Mg}\left(\mathrm{NO}_{3}\right)_{2} \cdot 6 \mathrm{H}_{2} \mathrm{O} /$ $\left.\mathrm{Ca}\left(\mathrm{NO}_{3}\right)_{2} \cdot 4 \mathrm{H}_{2} \mathrm{O} / \mathrm{TEOS}=1: 7: 4\right)$, then the mixture was stirred for 36 hours (at room temperature). After that, the solution was kept for 24 hours (at $50^{\circ} \mathrm{C}$ ) and dried for 24 hours (at $110^{\circ} \mathrm{C}$ ) to get the dry gel, which was ground to get the bredigite powder. The final bredigite powders were obtained from calcined dried gels at $600^{\circ} \mathrm{C}$ for 6 hours. All chemicals were purchased from Sinopharm Chemical Reagent Co., Ltd., Shanghai, People's Republic of China. The morphology of n-BD was characterized using a transmission electron microscope (TEM; JEM2010, JEOL, Tokyo, Japan).

PCL-PEG-PCL was prepared as follows: a three-necked flask was heated to $90^{\circ} \mathrm{C}$ after purging by nitrogen. The catalyst, stannous 2-ethylhexanoate and PEG methyl ether were added to the flask for 40 minutes and then CL (caprolactone) was introduced to the flask. The ring-opening polymerization reaction was carried out at $120^{\circ} \mathrm{C}$ for 24 hours. The obtained product was first dissolved in dichloromethane and then precipitated in a mixture of $n$-hexane and ethyl ether at a volumetric ratio of 3:7 for purification. This step was repeated several times to purify the product (PCL-PEG-PCL). The molecular weight $(\mathrm{Mw}=70,000)$ of PCL-PEG-PCL was determined by gel permeation chromatography.

\section{Preparation of $n-B P C$ scaffolds}

By using the solvent casting-particulate leaching method, the n-BPC scaffolds containing the n-BD content of 20 $\mathrm{wt} \%$ (n-BPC20) and $40 \mathrm{wt} \%$ (n-BPC40) were fabricated. ${ }^{15}$ PCL-PEG-PCL was added into chloroform to form a polymer solution, with continuous stirring to enable n-BD to disperse uniformly into the polymer solution. Particles of sodium chloride (used as porogens) with a size of around $450 \mu \mathrm{m}$ were introduced into the n-BPC slurry (sodium chloride: composite $=8: 1$ at weight ratio) and the mixture was stirred for 1 hour. The sodium chloride/composite mixture was cast into the molds $(\Phi 12 \times 2 \mathrm{~mm}$ and $\Phi 6 \times 6 \mathrm{~mm})$. To remove the solvent, the samples were dried for 24 hours (at $50^{\circ} \mathrm{C}$ ). After that, the samples were soaked in water at $37^{\circ} \mathrm{C}$ for 48 hours to leach out the sodium chloride particulates (the water was refreshed every 6 hours). The n-BPC scaffolds were obtained after removal from the water and were dried at $50^{\circ} \mathrm{C}$ for 12 hours. Using the same method, the PCLPEG-PCL scaffolds (used as controls) were prepared. The surface morphology and microstructure of the scaffolds were examined by scanning electron microscopy (SEM; S-3400N, Hitachi, Tokyo, Japan).

\section{Compressive strength, porosity, and water absorption of n-BPC scaffolds}

By using a Bose ElectroForce Smart Test the compressive strength of the n-BPC and PCL-PEG-PCL scaffolds were determined. By using A 5000-N static compression load and $0.1 \mathrm{~mm} / \mathrm{s}$ cross-head speed, the scaffolds with the size of $\Phi 6 \times 6 \mathrm{~mm}$ were placed between two parallel plates and compressed, and the load was used until the specimens were compressed to $50 \%$ of the original height. From the maximum point of the stress-strain curve, the compressive strengths of the specimens were obtained. The compressive strengths of n-BPC40 were found to be significantly lower than that of the n-BPC20 scaffolds. Therefore, in this study, the n-BPC20 samples were chosen for the further experiments.

By using the Archimedes method, the porosity of the scaffolds was determined in distilled water. The specimens were dried at $37^{\circ} \mathrm{C}$ for 48 hours, and the dry weight of the specimens was recorded as $p_{1}$.

The specimens were soaked in water (under vacuum) to force the water into the pores of the scaffolds. Then, the 
specimens were reweighed in water to get the measurement $p_{3}$. After that, the specimens were removed from the beaker and surface water droplets were dabbed off. The specimens were quickly reweighed in air to get the measurement $p_{2}$. The porosity of the specimens was calculated according to the formula: ${ }^{16}$ Porosity $=\left(p_{2}-p_{1}\right) /\left(p_{2}-p_{3}\right) \times 100 \%$, where $p_{1}$ is the dry weight, $p_{2}$ is the wet weight in air, and $p_{3}$ is the wet weight suspended in water.

After soaking the specimens into water for different time periods, the water absorption of the scaffolds was tested. The specimens $(\Phi 12 \times 2 \mathrm{~mm})$ were weighed and then soaked in water for $1,2,3,4,6$, and 8 hours. The specimens were removed from water at different time points, and the water on the scaffolds surfaces was wiped off, then the weights of the specimens were determined. The water absorption of the specimens was obtained using the following formula: Water absorption $=\left(W_{\mathrm{n}}-W_{\mathrm{d}}\right) /\left(W_{\mathrm{d}}\right) \times 100 \%$, where $W_{\mathrm{d}}$ is the starting weight of the specimens and $W_{\mathrm{n}}$ is the weight of the specimens after immersion for time $n$.

\section{Degradation of the n-BPC scaffolds in the Tris- $\mathrm{HCl}$ solution}

The degradation of the n-BPC and PCL-PEG-PCL scaffolds was determined by testing the weight change in Tris- $\mathrm{HCl}$ solution. ${ }^{17}$ The specimens $(\Phi 12 \times 2 \mathrm{~mm})$ were weighed and then immersed in the Tris- $\mathrm{HCl}$ solution $\left(\right.$ at $37^{\circ} \mathrm{C}$ ) in a shaking water bath for $1,2,3,5,7$, and 10 weeks. The solution was replaced once a week. At different time points, the samples were washed with water and dried at $50^{\circ} \mathrm{C}$ for 24 hours. The weight loss of the specimens was calculated using the following formula: Weight loss ratio $=\left(W_{\mathrm{n}}-W_{\mathrm{s}}\right) /\left(W_{\mathrm{s}}\right) \times 100 \%$, where $W_{\mathrm{s}}$ is the starting weight and $W_{\mathrm{n}}$ is the weight of the specimens after immersion for time $n$.

\section{Cell proliferation and morphology}

The MG63 cells (ATCC) were purchased from the Chinese Academy of Sciences (Shanghai, People's Republic of China) and were cultured with Dulbecco's Modified Eagle's Medium supplemented with glutamine (Gibco, Grand Island, NY, USA). In addition, the medium contained $10 \%$ $(\mathrm{v} / \mathrm{v})$ fetal calf serum purchased from Sijiqing (Hangzhou, People's Republic of China) and 1\% (v/v) antibiotics. The cells were grown in a $100 \%$ standard humidified atmosphere with $5 \% \mathrm{CO}_{2}$ and at $37^{\circ} \mathrm{C}$.

The MG63 cells were seeded onto the scaffolds $(\Phi 12 \times 2 \mathrm{~mm})$ of $\mathrm{n}-\mathrm{BPC}$ and PCL-PEG-PCL in 24-well plates. At 1, 3, and 5 days, the cell proliferation was tested using a Cell Counting Kit 8 (CCK-8, Sigma-Aldrich, St Louis,
MO, USA). The specimens were gently rinsed three times with phosphate-buffered saline (PBS) at the specific time points. The results were expressed as mean absorbance values (optical density [OD]) at $450 \mathrm{~nm}$ and were obtained using a microplate reader (Synergy HT, Bio-tek, Winooski, VT, USA).

The cell morphology of MG63 cells was examined by visualizing the filamentous actin of the cytoskeleton by confocal laser scanning microscopy (Leica TCS SP2; Leica Microsystems, Heidelberg, Germany). The samples were placed in a 24-well plate and the cells were seeded on the specimens. To remove the unattached cells, the specimens were washed with PBS after 5 days of culture. According to the protocol, the cells on the specimens were fixed with $2.5 \%$ glutaraldehyde for 20 minutes (at room temperature), and the samples were then permeabilized with $0.1 \%$ Triton X-100 in PBS for 20 minutes. The cells were stained with 4,6-diamidino-2-phenylindole (Sigma) and fluoresceinisothiocyanate (Sigma) after washing three times with PBS.

\section{Alkaline phosphatase activity}

The MG63 cells were seeded on the specimens in 24-well plates and cultured (at $37^{\circ} \mathrm{C}, 100 \%$ humidity atmosphere, and $5 \% \mathrm{CO}_{2}$ ) for different time periods. At 7 and 10 days, in the osteogenic medium, the alkaline phosphatase (ALP) activity of the cells was determined by an ALP assay. The cell lysates were obtained by addition of $1 \mathrm{~mL}$ of $0.2 \%$ Nonidet $\mathrm{P}-40$ solution (NP-40) to each well at the specific time points. Then, $50 \mu \mathrm{L}$ of the $1 \mathrm{mg} / \mathrm{mL} p$-nitrophenylphosphate (Sigma) substrate solution $(\mathrm{pH}=9)$ containing $0.1 \mathrm{~mol} / \mathrm{L}$ glycine and $0.5 \mathrm{mmol} / \mathrm{L} \mathrm{MgCl}_{2}$ in $1 \mathrm{M}$ diethanolamine buffer was added to each well and incubated at $37^{\circ} \mathrm{C}$ for 20 minutes, and the reaction was stopped by adding $0.1 \mathrm{M}$ sodium hydroxide $(100 \mu \mathrm{L})$. Using a microplate reader (SPECTR Amax 384, Molecular Devices, Sunnyvale, CA, USA), at the wavelength of $405 \mathrm{~nm}$, the OD value was determined, and the ALP activity was expressed as the OD value per total protein. By using the bicinchoninic acid protein assay kits, the total protein content was obtained using a series of bovine serum albumin standards. The ALP activity of cell lysates was determined by normalizing it to the total protein content.

\section{Histological elevation from animal model}

Rabbits (New Zealand white rabbits, 5 months old, and $2 \mathrm{~kg}$ average weight) were used in this study upon approval from the Animal Research Committee of the Ninth People's Hospital (Shanghai, People's Republic of China). All experiments were performed following relevant institutional and national 
guidelines and regulations in People's Republic of China. The rabbits were divided into three groups (total: 24 rabbits) and anesthetized by intramuscular injection of Zoletil 50 and $2 \%$ Rompon. Surgery on the rabbits was carried out under sterile condition. To expose the distal femoral epiphysis, lateral and medial approaches were carried out in left knees (shaved of fur), and bone defects were made by using a medium speed burr. The samples $(\Phi 6 \times 6 \mathrm{~mm})$ were implanted into the cavity after the bone defects were washed with physiological saline. At 6 and 12 weeks, the rabbits were killed using an overdose of pentobarbital to obtain animal experimental samples (extracted femora). At certain implantation time period, some samples were tested using X-ray microradiography to observe the process of the new bone formation.

Fixing with $10 \%$ buffered formaldehyde for 2 weeks, the samples were dehydrated in successive concentrations of ethanol (from $75 \%$ to $100 \%$ ) and then embedded in polymethylmethacrylate. By using a microtome (Leica SP1600, Leica Microsystems), the samples were sectioned perpendicular to the implants (150 $\mu \mathrm{m}$ in thickness) after hardening. Before staining with hematoxylin-eosin (H\&E), the sample sections were ground polished (final thickness of $\sim 50 \mu \mathrm{m}$ ). Using a light microscope, the histological sections of the samples were observed after staining; in the same section, at least five images were randomly obtained. The ratio of new bone formation was expressed as the percentage of the new bone area within the defect area using the image analytical software Image-ProPlus (Media Cybernetics, Rockville, MD, USA).

\section{Statistical analysis}

In this study, data were obtained using Origin 8.0 (Origin Lab Corporation, Northampton, MA, USA) and expressed as mean \pm standard deviation. Statistical comparisons were performed using one-way analysis of variance with post hoc tests. The notation "*" denotes $P<0.05$.

\section{Results and discussion Composition and structure of $n-B D$ and n-BPC scaffolds}

The morphology and nanostructure of the n-BD from TEM images is shown in Figure 1A. The synthetic n-BD scaffolds were almost homogeneously spherical-shaped particles that were 50-80 nm in diameter. The wide-angle X-ray diffraction pattern of n-BD is shown in Figure 1B. Only one broad reflection at $2 \theta=15^{\circ}-35^{\circ}$ can be visually found, revealing that $n-B D$ showed an amorphous structure. Figure $1 \mathrm{C}$ reveals the infrared pattern of n-BD. The peak at 1,093, 799, and $467 \mathrm{~cm}^{-1}$ showed the $\mathrm{Si}-\mathrm{O}-\mathrm{Si}$ antisymmetric stretching vibration, the
$\mathrm{Si}-\mathrm{O}$ symmetric stretching vibration, and the $\mathrm{Si}-\mathrm{O}$ flexural vibration, respectively. Table 1 lists the compressive strength and porosity of the n-BPC and PCL-PEG-PCL scaffolds. It was found that the compressive strength of n-BPC20 was $4.7 \mathrm{MPa}$, which was obviously higher than n-BPC40 (1.9 MPa) and PCL-PEG-PCL (2.8 MPa) scaffolds.

The n-BD content in the composite had obviously affected the compressive strength of the scaffolds, and suitable n-BD content would improve the compressive strength of the scaffolds, whereas more n-BD content would decrease the compressive strength. The decrease in the compressive strength of n-BPC40 (1.9 MPa) compared with n-BPC20 (4.7 MPa) is because $n-B D$ is a brittle material whereas PCL-PEG-PCL is a tough material. More n-BD into polymer would cause the decrease in the mechanical strength of the composite. Regarding the porosity, no obvious difference was found among the n-BPC20 (81\%), n-BPC40 (77\%), and PCL-PEG-PCL (78\%) scaffolds. Furthermore, the compressive strength of composite scaffolds was 4.7 MPa, which was similar to the strength of cancellular bone (3-8 MPa) of the human body. ${ }^{18}$ Therefore, in this study, the n-BPC20 samples were chosen for further experiments.

For bone tissue ingrowth, scaffolds should have a threedimensional porous structure (porosity: no less than $70 \%$, pore size: $100-600 \mu \mathrm{m})$, which was regarded as the porosity requirement for the ingrowth of new bone tissue. ${ }^{19}$ Figure 2 presents the SEM images of the samples, which showed the surface morphology of the n-BPC20 and PCL-PEG-PCL scaffolds. It was observed that the majority of the pores of the scaffolds were macropores, with the size of around $400 \mu \mathrm{m}$, and these macropores of the scaffolds were well interconnected, which would favor bone cell/tissue ingrowth. In this study, although bioactive inorganic materials had superior bone-forming activities, they were brittle and difficult to shape. ${ }^{20}$ Composite scaffolds containing polymers and bioactive inorganic materials have attracted growing attention for bone tissue regeneration. ${ }^{21}$ Therefore, it can be suggested that the introduction of the bioactive material n-BD into PCL-PEG-PCL was a good method to prepare bioactive composite scaffolds for bone repair.

\section{Water absorption and degradability of $n$-BPC scaffolds}

The water absorption of the n-BPC and PCL-PEG-PCL scaffolds after immersion into water for different time points is shown in Figure 3. The water absorption of both the n-BPC and PCL-PEG-PCL scaffolds improved with time; it was found that the water absorption of the n-BPC scaffolds was $148 \%$, while that of the PCL-PEG-PCL scaffolds was 

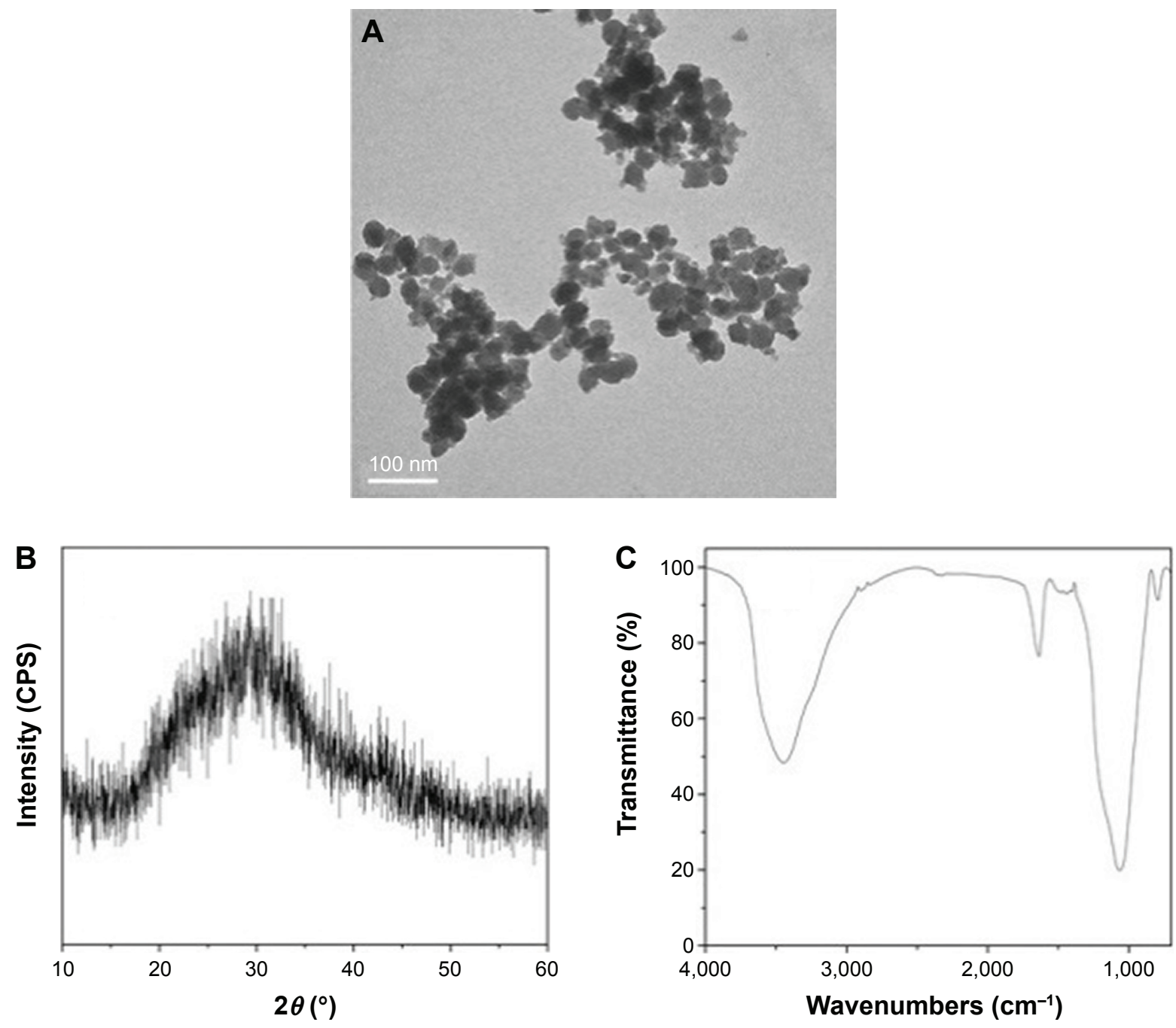

Figure I TEM images (A), wide-angle XRD (B) and FTIR patterns (C) of n-BD.

Abbreviations: $\mathrm{n}-\mathrm{BD}$, nanobredigite; TEM, transmission electron microscopy; XRD, X-ray diffraction; FTIR, Fourier transform infrared spectroscopy.

$77 \%$ after immersion into water for 24 hours, respectively. The water absorption is an important factor for degradation of and cell responses to the biomaterial scaffolds, and improved water absorption of scaffolds would promote the interactions between the cells and biomaterials..$^{22}$ The results showed that the water absorption of the n-BPC scaffolds was obviously higher than that of the PCL-PEG-PCL scaffolds, revealing that the incorporation of n-BD into PCL-PEG-PCL

Table I Porosity and compressive strength of n-BPC and PCLPEG-PCL scaffolds

\begin{tabular}{lll}
\hline Scaffolds & Compressive strength $\mathbf{( M P a )}$ & Porosity $(\%)$ \\
\hline PCL-PEG-PCL & $2.8 \pm 2$ & $78 \pm 4$ \\
n-BPC20 & $4.7 \pm 1$ & $81 \pm 3$ \\
n-BPC40 & $1.9 \pm 2$ & $77 \pm 3$ \\
\hline
\end{tabular}

Abbreviations: $n-B P C, n-B D / P C L-P E G-P C L$ composite; $n-B D$, nanobredigite; $P C L-$

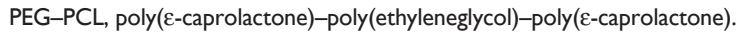

significantly increased the water absorption of the n-BPC scaffolds. In short, the addition of inorganic bioactive materials into polymers was a good method to enhance the mechanical properties and water absorption of the polymerbased composites.

Figure 4 shows the weight loss of the n-BPC and PCLPEG-PCL scaffolds after soaking in the Tris- $\mathrm{HCl}$ solution for different time points. It was found that the weight loss for both the samples rose with time, and the weight loss of the n-BPC scaffolds was $83 \mathrm{w} \%$ after soaking in the Tris- $\mathrm{HCl}$ solution for 12 weeks, while that of the PCL-PEG-PCL scaffolds was $49 \mathrm{wt} \%$. The degradability of the implanted scaffolds should be coincident with the new bone growth and gradually replaced by the new bone. ${ }^{23}$ The results showed that the degradation rate of the n-BPC scaffolds was faster than that of the PCL-PEG-PCL scaffolds, indicating that the addition of n-BD into PCL-PEG-PCL obviously improved the 

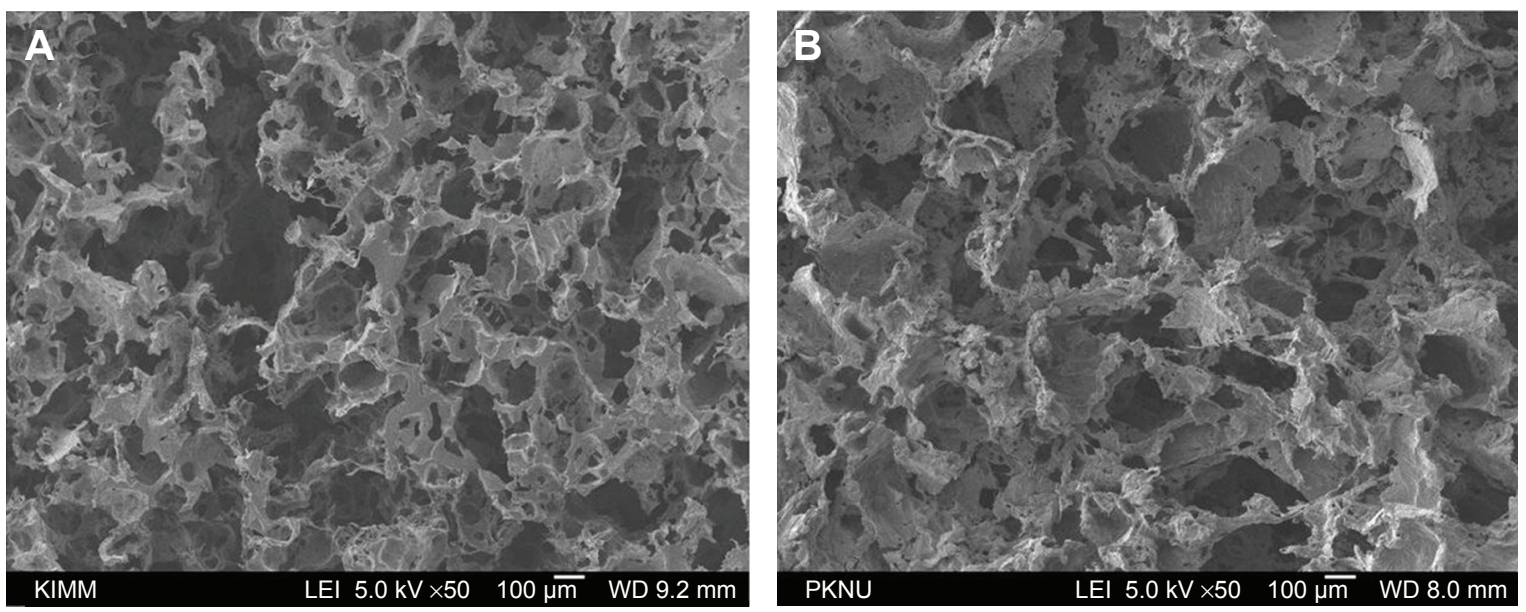

Figure 2 SEM images of $n-B P C(A)$ and PCL-PEG-PCL (B) scaffolds.

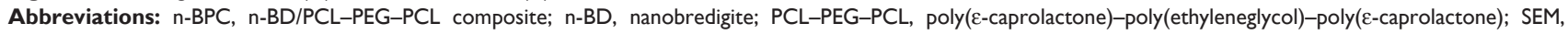
scanning electron microscopy.

degradability of the scaffolds compared with PCL-PEG-PCL alone. It could be suggested that the improved water absorption of n-BPC scaffolds resulted in an improved degradability of the n-BD and PCL-PEG-PCL scaffolds. Therefore, the degradability of n-BPC scaffolds was significantly higher than that of the PCL-PEG-PCL scaffolds.

\section{Cell proliferation and morphology}

Figure 5 shows the proliferation of the MG63 cells on the scaffolds at different time points. It was found that the OD values of the cells on both the n-BPC and PCL-PEG-PCL scaffolds increased with time. At 1 day, no significant difference in the OD value between n-BPC and PCL-PEG-PCL scaffolds was observed. However, at 3 and 5 days, the OD value of the n-BPC scaffold was significantly higher than that

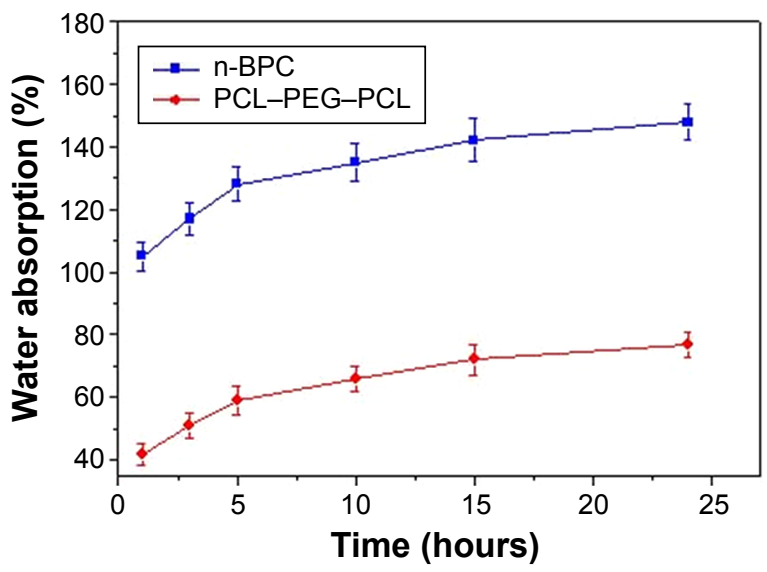

Figure 3 Changes in the water absorption of $n-B P C$ and PCL-PEG-PCL scaffolds with time.

Abbreviations: $n-B P C, n-B D / P C L-P E G-P C L$ composite; $n-B D$, nanobredigite; PCLPEG-PCL, poly( $\varepsilon$-caprolactone)-poly(ethyleneglycol)-poly( $\varepsilon$-caprolactone). of the PCL-PEG-PCL scaffolds. Our results indicated that the n-BPC scaffolds could promote the proliferation of MG63 cells compared with the PCL-PEG-PCL scaffolds.

Figure 6 shows the cytoskeletal morphology (confocal laser scanning microscopy images) of the MG63 cells on both the n-BPC and PCL-PEG-PCL scaffolds. The MG63 cells could attach and grow into both the n-BPC and PCLPEG-PCL scaffolds. At 5 days, it was found that the number of cells on the n-BPC scaffolds was significantly higher than that on the PCL-PEG-PCL scaffolds. The results indicated that the n-BPC scaffolds were favorable for the growth of MG63 cells. Therefore, we suggested that the incorporation of bioactive materials of $\mathrm{n}-\mathrm{BD}$ into polymers was a good method to prepare the n-BPC scaffolds that promoted cell proliferation and ingrowth into the scaffolds as compared

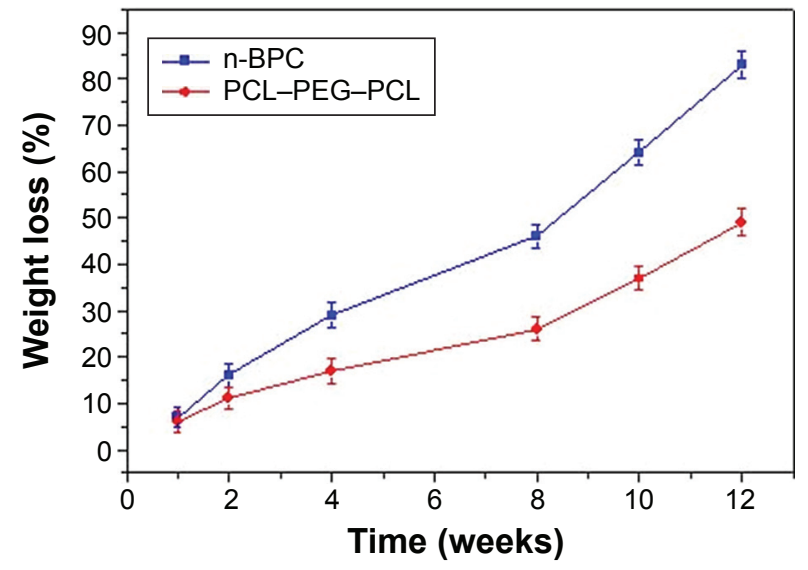

Figure 4 Weight loss of n-BPC and PCL-PEG-PCL scaffolds after soaking in the Tris- $\mathrm{HCl}$ solution for different time periods.

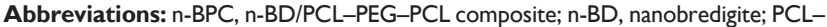
PEG-PCL, poly( $\varepsilon$-caprolactone)-poly(ethyleneglycol)-poly( $\varepsilon$-caprolactone). 


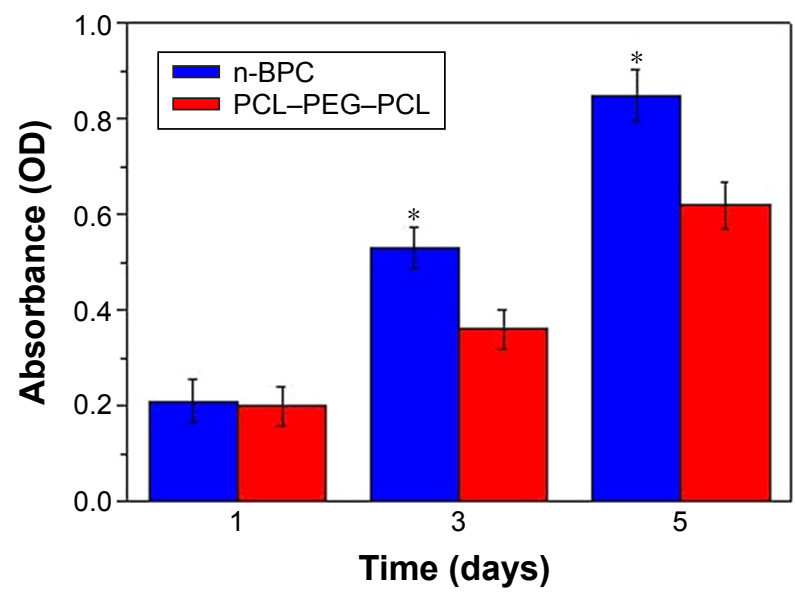

Figure 5 Proliferation of MG63 cells cultivated on n-BPC and PCL-PEG-PCL scaffolds for I, 3 , and 5 days.

Notes: Data are represented as mean \pm standard deviation $(n=5)$; asterisk $(*)$ indicates significant difference.

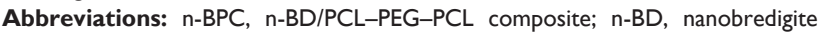
PCL-PEG-PCL, poly( $\varepsilon$-caprolactone)-poly(ethyleneglycol)-poly( $\varepsilon$-caprolactone); OD, optical density.

to the PCL-PEG-PCL scaffolds. The proliferation of MG63 cells on the n-BPC and PCL-PEG-PCL scaffolds improved with time, indicating that the scaffolds had good cytocompatibility. Furthermore, at 5 days, it was found that the proliferation and growth of the cells into the n-BPC scaffolds was obviously better than that on the PCL-PEG-PCL scaffolds. Our results suggested that the n-BPC scaffolds might have better cytocompatibility than the PCL-PEG-PCL scaffolds, thereby remarkably promoting the cell proliferation and growth into the n-BPC scaffold.
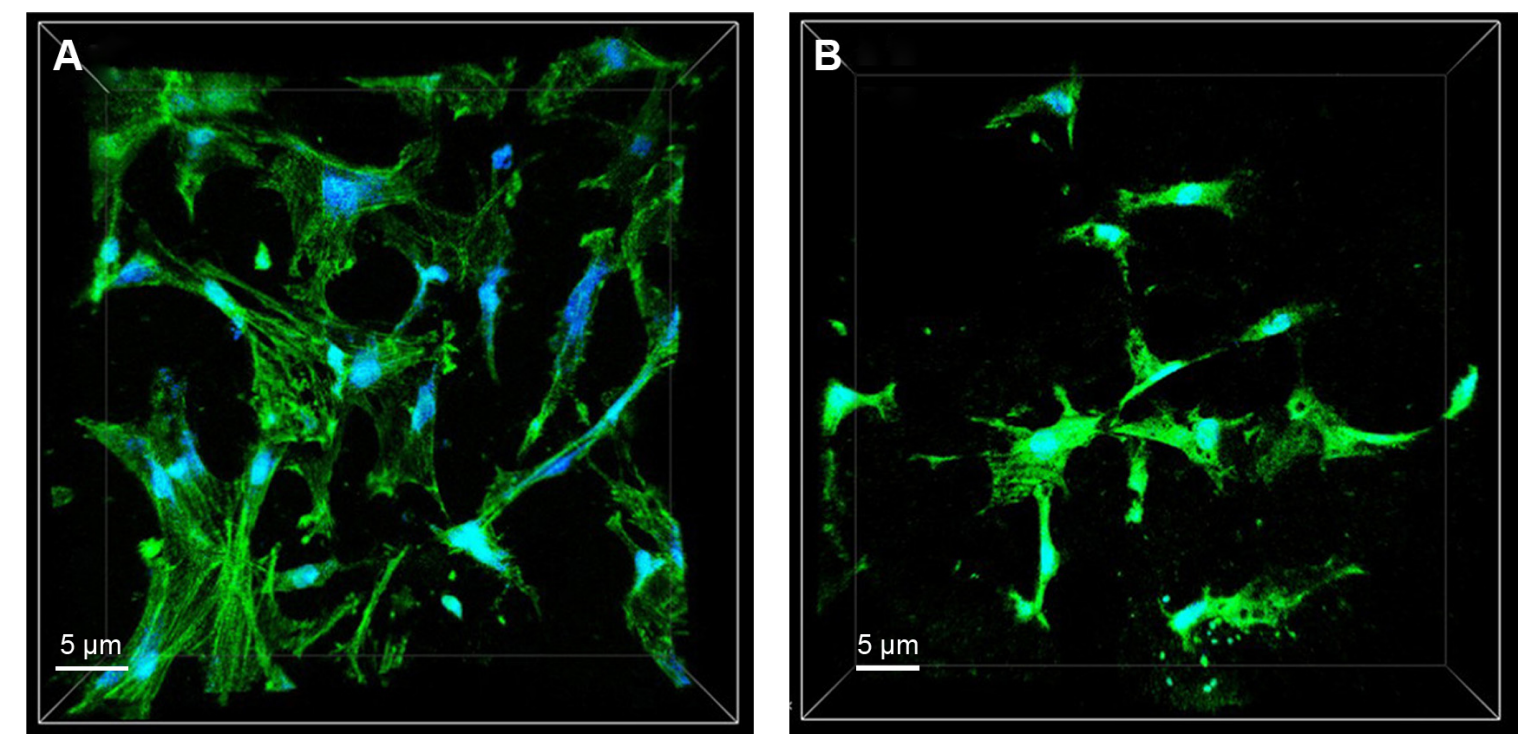

Figure 6 CLSM images of cytoskeletal morphology of the MG63 cells cultivated on n-BPC (A) and PCL-PEG-PCL (B) scaffolds for 5 days.

Abbreviations: CLSM, confocal laser scanning microscopy; $n-B P C, n-B D / P C L-P E G-P C L$ composite; n-BD, nanobredigite; PCL-PEG-PCL, poly( $(\varepsilon-c a p r o l a c t o n e)-$ poly(ethyleneglycol)-poly(E-caprolactone). 


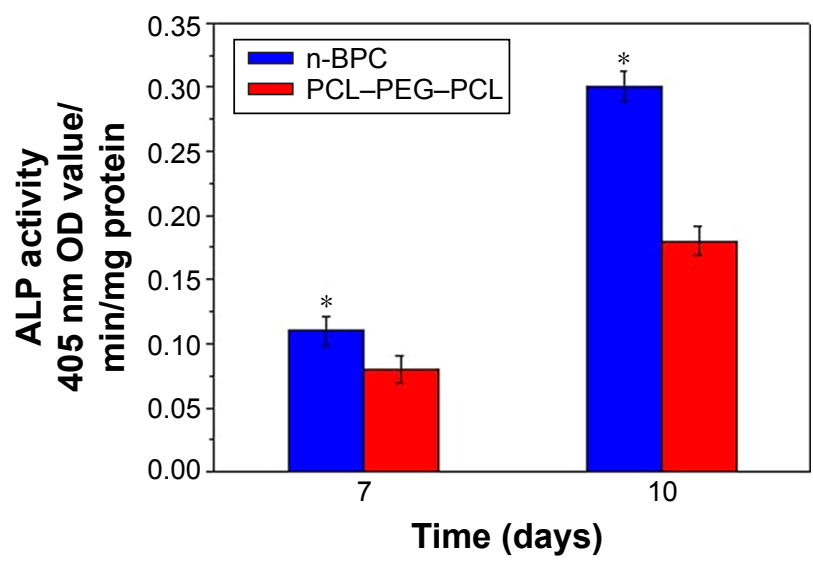

Figure 7 ALP of MG63 cells cultivated on n-BPC and PCL-PEG-PCL scaffolds for 7 and 10 days.

Notes: Data are represented as mean \pm standard deviation $(n=5)$; asterisk $(*)$ indicates significant difference.

Abbreviations: ALP, alkaline phosphatase; n-BPC, n-BD/PCL-PEG-PCL composite; n-BD, nanobredigite; PCL-PEG-PCL, poly(E-caprolactone)-poly(ethyleneglycol)poly(E-caprolactone); OD, optical density.

Some studies have indicated that the dissolution of $\mathrm{Si}, \mathrm{Mg}$, and $\mathrm{Ca}$ ionic products from bioactive materials such as bioglass or bioceramics promoted osteoblast proliferation, differentiation, and gene expression. ${ }^{27}$ The n-BPC scaffolds could be degradable, which contained the dissolution of both n-BD and PCL-PEG-PCL. The dissolution of $\mathrm{n}-\mathrm{BD}$ would produce some $\mathrm{Si}, \mathrm{Ca}$, and $\mathrm{Mg}$ ions in the solution. Therefore, it can be suggested that the continuous dissolution of the scaffolds might produce a microenvironment containing $\mathrm{Si}, \mathrm{Ca}$, and $\mathrm{Mg}$ ions that might promote cell responses (cell adhesion, proliferation, and differentiation).

\section{X-ray microradiographs and histological evaluations}

The results in Figure 8 show the of X-ray microradiographs of samples after the in vivo implantation of the n-BPC and PCL-PEG-PCL scaffolds at different time points. At 6 weeks, the boundary between the material and the bone tissue became unclear, suggesting that mineralization had occurred and that the density of the n-BPC scaffold increased (Figure 8A). At 12 weeks, the boundary between the material and the tissue disappeared, and the density of new bone was similar to that of the host bone, indicating that the new bone tissue grew into the n-BPC scaffolds in bone defects (Figure 8C). However, at 6 weeks, the bone defects were still darker than the host bone tissue after implantation of the PCL-PEG-PCL scaffolds, and the density of the material was lower than that of the host bone tissue, showing less new bone tissue growth into the PCL-PEG-PCL scaffolds (Figure 8B). At 12 weeks, the density of scaffolds increased compared to that at 6 weeks, illustrating new bone growth into the PCL-PEG-PCL scaffold and increased density of the scaffolds (Figure 8D). The results also confirmed that the n-BPC and PCL-PEG-PCL scaffolds were biocompatibe with host bone tissue.
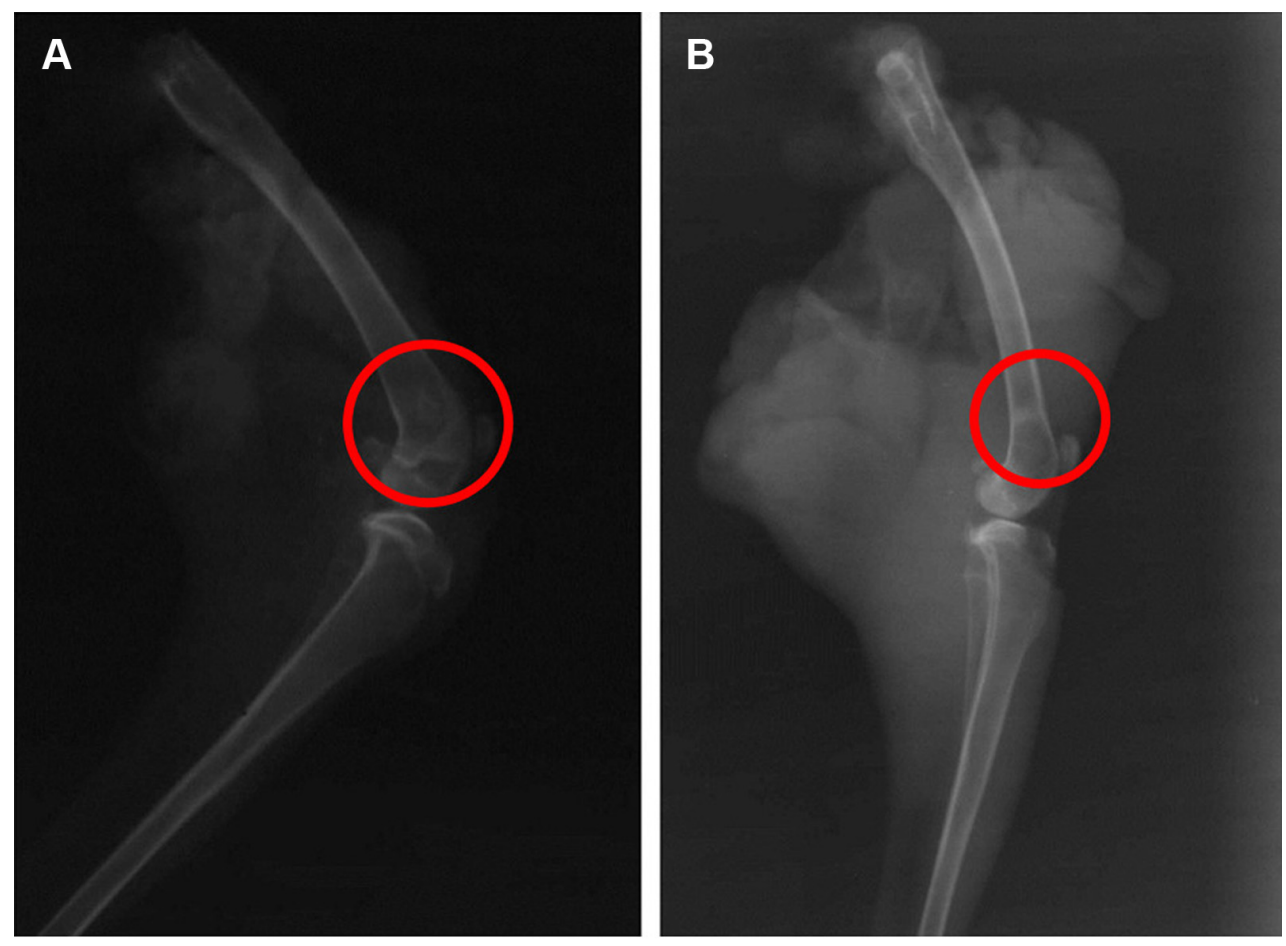

Figure 8 (Continued) 

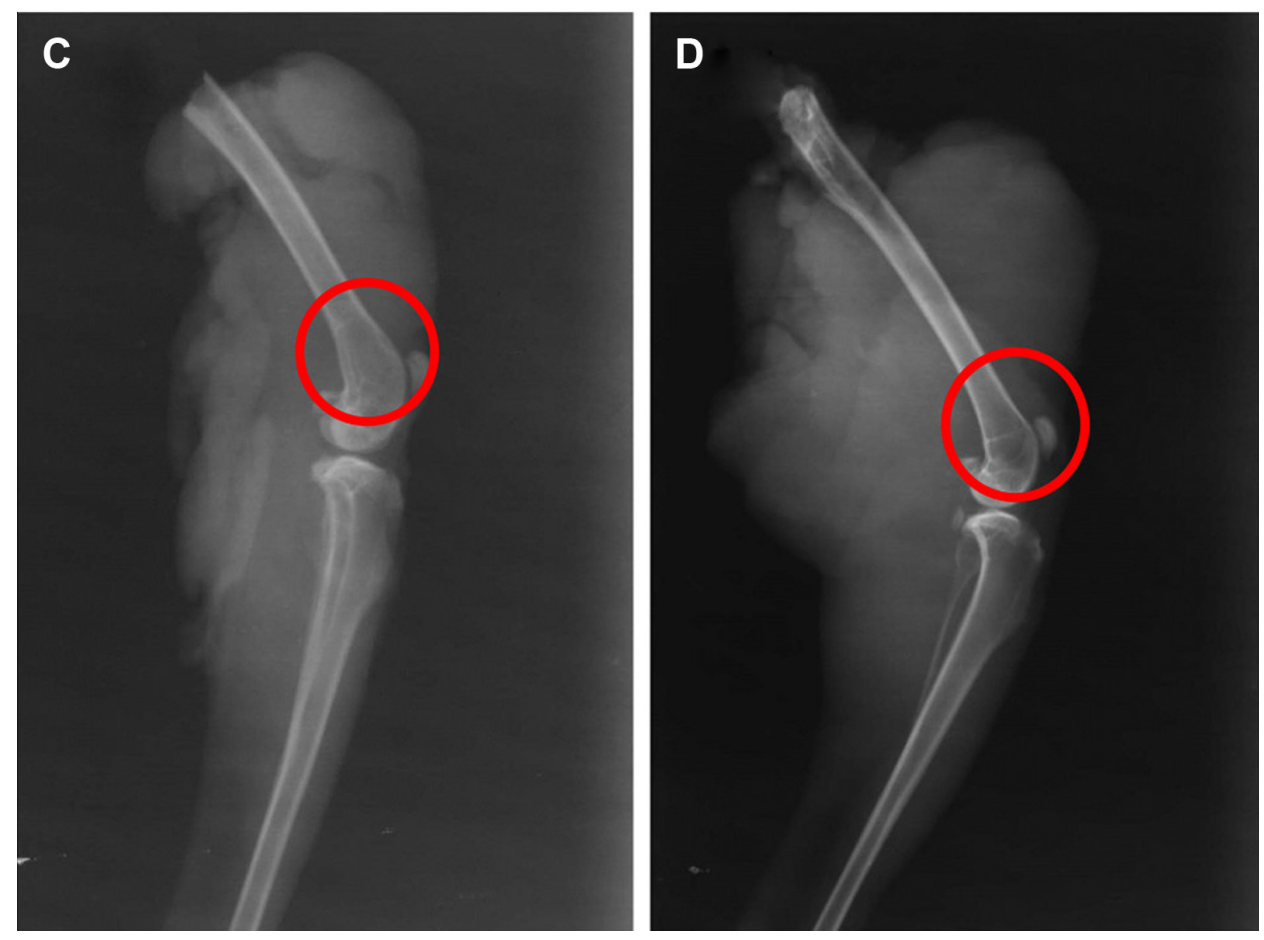

Figure 8 X-ray microradiographs of the defects of rabbit femora after in vivo implantation of n-BPC (A, C) and PCL-PEG-PCL (B, D) scaffolds for 6 and I2 weeks. Notes: Implantation time: (A, B) 6 weeks and (B, D) 12 weeks; red circles represent implantation sites.

Abbreviations: n-BPC, n-BD/PCL-PEG-PCL composite; n-BD, nanobredigite; PCL-PEG-PCL, poly(E-caprolactone)-poly(ethyleneglycol)-poly( $(\varepsilon-c a p r o l a c t o n e)$.

Figure 9 shows the photographs of H\&E stained histological sections of new bone formation and materials degradation after the in vivo implantation of the n-BPC and PCLPEG-PCL scaffolds for different time points. At 6 weeks, some new bone tissue growth was observed in the n-BPC scaffolds, while less new bone tissue growth was observed in the PCL-PEG-PCL scaffolds. Obviously, the newly formed bone tissue in the PCL-PEG-PCL scaffolds was less than that in the n-BPC scaffolds. At 12 weeks, a large amount of newly formed bone tissues were found in the n-BPC scaffolds while it was much less in PCL-PEG-PCL scaffolds, indicating that the new bone tissues grew into scaffolds while the materials were gradually degradable. Meanwhile, some newly formed bone tissues were observed in the PCL-PEG-PCL scaffolds along with the materials degradability. Clearly, the amount of new bone tissue in the n-BPC scaffolds was obviously higher than that in the PCL-PEG-PCL scaffolds.

Figure 10 shows the changes of the new bone formation ratio in the scaffolds, which were quantitatively analyzed by histological sections. It can be seen that the new bone formation ratio enhanced with time for both the n-BPC and PCL-PEG-PCL scaffolds. Moreover, at 6 and 12 weeks, the new bone formation ratio for the n-BPC scaffolds was $57 \%$ and $82 \%$, while that for the PCL-PEG-PCL scaffolds was $35 \%$ and $52 \%$, respectively. Our results indicated that the new bone formation ratio for the n-BPC scaffolds was markedly higher than that for the PCL-PEG-PCL scaffolds at both 6 and 12 weeks.

Ideal biomaterials not only interact actively with cells but also stimulate tissue regeneration. ${ }^{28}$ Our results indicated that new bone tissues gradually increased and the materials continued to reduce for both the n-BPC and PCL-PEG-PCL scaffolds after implantation into bone defects for different time periods. A large quantity of newly formed bone tissue was observed in the n-BPC scaffolds at 12 weeks, which was obviously higher than that in the PCL-PEG-PCL scaffolds. Compared with the PCL-PEG-PCL scaffolds, it is likely that the well-interconnected macroporous n-BPC scaffolds containing n-BD provided a suitable microenvironment for the interaction between scaffolds and bone tissue, and thus promoted bone tissue growth into the scaffolds. ${ }^{29}$ Moreover, the release of $\mathrm{Si}, \mathrm{Ca}$, and $\mathrm{Mg}$ ions from the n-BPC scaffolds (dissolution) produced a microenvironment that might stimulate cell growth and new bone tissue regeneration. Furthermore, n-BD in the n-BPC scaffolds might promote scaffold degradation in vivo, which might enhance tissue regenerations, indicating good osteogenesis. This suggests that the n-BPC scaffolds as bioactive implants might have special biofunctions to stimulate tissue regeneration, which improved new bone formation compared with the 

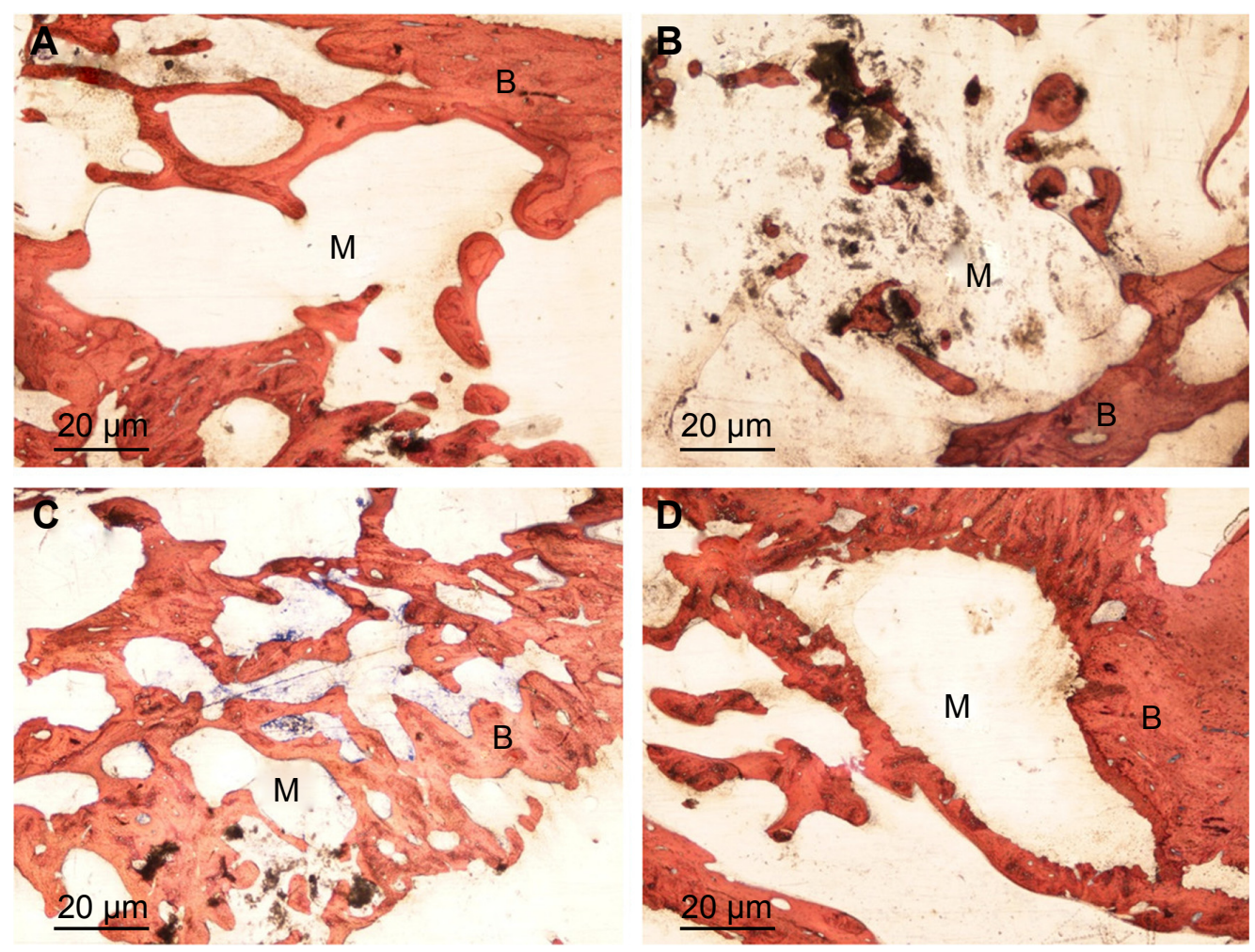

Figure 9 Histological evaluation (H\&E staining) depicting material degradation and new bone formation after in vivo implantation of n-BPC (A, C) and PCL-PEG-PCL (B, D) scaffolds for 6 and 12 weeks, respectively.

Abbreviations: B, new bone; H\&E, hematoxylin-eosin; M, materials; n-BPC, n-BD/PCL-PEG-PCL composite; n-BD, nanobredigite; PCL-PEG-PCL, poly(ع-caprolactone)poly(ethyleneglycol)-poly(E-caprolactone).

PCL-PEG-PCL scaffolds. The n-BPC scaffolds could be an excellent candidate for bone repair applications.

\section{Conclusion}

Bioactive scaffolds of the n-BPC with an interconnected macroporous structure were fabricated. The results suggested

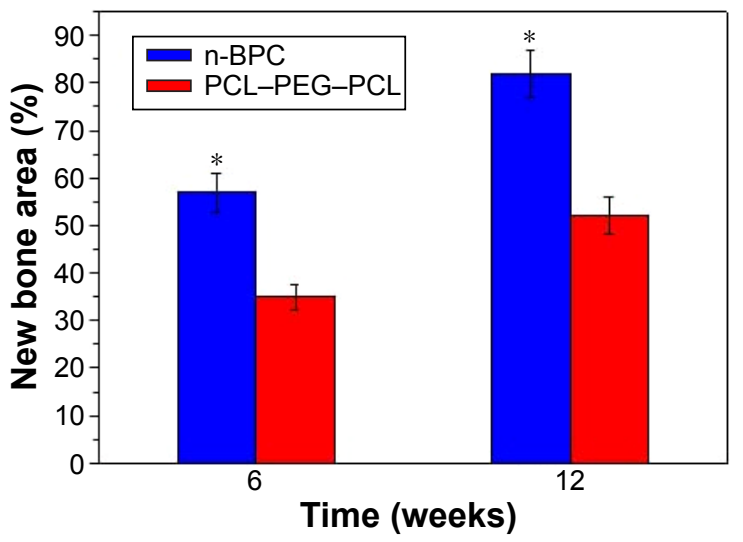

Figure 10 Quantitative analysis of the new bone area by histological observation after in vivo implantation of n-BPC and PCL-PEG-PCL scaffolds for 6 and 12 weeks.

Notes: Data are represented as mean \pm standard deviation $(n=5)$; asterisk $\left(^{*}\right)$ indicates significant difference.

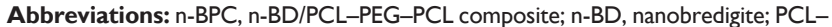
PEG-PCL, poly( $\varepsilon$-caprolactone)-poly(ethyleneglycol)-poly( $\varepsilon$-caprolactone). that the incorporation of n-BD into PCL-PEG-PCL significantly improved water absorption, compressive strength, and degradability of the n-BPC scaffolds compared with the PCL-PEG-PCL scaffolds. Further more the proliferation and ALP activity of MG63 cells on the n-BPC scaffolds were found to be remarkably higher than that on PCLPEG-PCL scaffolds, indicating that the n-BPC scaffolds promoted cell proliferation and differentiation. Moreover, the histological evaluation results revealed that the in vivo osteogenesis of n-BPC scaffolds was obviously enhanced as compared with the PCL-PEG-PCL scaffolds, indicating that the n-BPC scaffolds promoted bone regeneration. In short, the incorporation of n-BD into PCL-PEG-PCL was a useful method to fabricate bioactive scaffolds with good biocompatibility and osteogenesis that could be used for bone repair application.

\section{Acknowledgments}

This study was supported by grants from the Major International Joint Research Project between the People's Republic of China and Republic of Korea (81461148033), the National High Technology Research and Development Program of China (863 Program) (2014AA021202), the National 
Natural Science Foundation of China (Numbers 81271705 , 31271031), and the National Research Foundation of Korea (NRF) (grant number: NRF-2014K2A2A7066637).

\section{Disclosure}

The authors report no conflicts of interest in this work.

\section{References}

1. Wu LL, Berengere JC, Feyerabend F. Effects of extracellular magnesium on the differentiation and function of human osteoclasts. Acta Biomater. 2014;10:2843-2854.

2. Christel T, Christ S, Barralet JE, Groll J, Gbureck U. Chelate bonding mechanism in a novel magnesium phosphate bone cement. J Am Ceram Soc. 2015;98:694-697.

3. Liu Y, Kumar S, Kwag J, Ra C. Magnesium ammonium phosphate formation, recovery and its application as valuable resources: a review. J Chem Technol Biotechnol. 2013;88:181-189.

4. Shi MC, Zhou YH, Shao J, et al. Stimulation of osteogenesis and angiogenesis of hBMSCs by delivering Si ions and functional drug from mesoporous silica nanospheres. Acta Biomaterialia. 2015;21:178-189.

5. Jayalekshmi AC, Sharma P. Gold nanoparticle incorporated polymer/ bioactive glass composite for controlled drug delivery application. Colloids Surf B Biointerfaces. 2015;126:280-287.

6. Vorndran E, Ewald A, Muller F, Zorn K, Kufner A, Gbureck U. Formation and properties of magnesium-ammonium-phosphate hexahydratebiocements in the $\mathrm{Ca}-\mathrm{Mg}-\mathrm{PO} 4$ system. J Mater Sci Mater Med. 2011;22:429-436.

7. Zhai WY, Lu HG, Wu CT, Chen L, Lin XT, Chang J. Stimulatory effects of the ionic products from $\mathrm{Ca}-\mathrm{Mg}-\mathrm{Si}$ bioceramics on both osteogenesis and angiogenesis in vitro. Acta Biomater. 2013;9:2843-2854.

8. Yi DL, Wu CT, Ma B, Ji H, Zheng XB, Chang J. Bioactive bredigite coating with improved bonding strength, rapid apatite mineralization and excellent cytocompatibility. J Biomater Appl. 2014;28:1343-1353.

9. Stulajterova R, Medvecky L, Giretova M, Sopcak T. Structural and phase characterization of bioceramics prepared from tetracalcium phosphate-monetite cement and in vitro osteoblast response. $J$ Mater Sci Mater Med. 2015;26:7680-7686.

10. Wu CT, Chang JA, Wang JY, Ni SY, Zhai WY. Preparation and characteristics of a calcium magnesium silicate (bredigite) bioactive ceramic. Biomaterials. 2005;26:2925-2931.

11. Guo ST, Huang YY, Wei T, et al. Amphiphilic and biodegradable polyethylene glycol-block-(polycaprolactone-graft-poly(2-(dimethylamino) ethyl methacrylate) as an effective gene carrier. Biomaterials. 2011; 32:879-889.

12. Li RT, Li XL, Xie L. Preparation and evaluation of PEG-PCL nanoparticles for local tetradrine delivery. Int J Pharm. 2009;379:158-166.

13. Khoee S, Kardani M. Preparation of PCL/PEG superporous hydrogel containing drug-loaded nanoparticles: the effect of hydrophobic-hydrophilic interface on the physical properties. Eur Polym J. 2014;58:180-190.

14. Columbus S, Krishnan L, Krishnan K. Relating pore size variation of poly( $\varepsilon$-caprolactone) scaffolds to molecular weight of porogen and evaluation of scaffold properties after degradation. J Biomed Mater Res B Appl Biomater. 2014;102:789-796.
15. Scaffaro R, Lopresti1 F, Botta1 L, Rigogliuso S, Ghersi G. Melt processed PCL/PEG Scaffold with discrete pore size gradient for selective cellular infiltration. Macromol Mater Eng. 2016;301(2):182-190.

16. Przekora A, Palka K, Ginalska G. Biomedical potential of chitosan/HA and chitosan/beta-1,3-glucan/HA biomaterials as scaffolds for bone regeneration - a comparative study. Mater Sci Eng C Mater Biol Appl. 2016;58:891-899.

17. Liu W, Zhai D, Huan Z, Wu C, Chang J. The SBF solution is usually used to test the bioactivity of the biomaterials (apatite formation on the surface of biomaterial) in vitro. Acta Biomater. 2015;21:217-227.

18. Jiang CP, Huang JR, Hsieh MF. Fabrication of synthesized PCL-PEGPCL tissue engineering scaffolds using an air pressure-aided deposition system. Rapid Prototyping J. 2011;17:288-297.

19. Hruschka V, Saeed A, Slezak Paul A, et al. Evaluation of a thermoresponsive polycaprolactone scaffold for in vitro three-dimensional stem cell differentiation. Tissue Eng Part A. 2015;21:310-319.

20. Rocha O, Agda C, Sandhra M, Leite F. Development of biodegradable polyurethane and bioactive glass nanoparticles scaffolds for bone tissue engineering applications. J Biomed Mater Res B. 2012;100B: 1387-1396.

21. Ryszkowska L, Auguscik M, Sheikh A. Biodegradable polyurethane composite scaffolds containing Bioglass $(\mathrm{R})$ for bone tissue engineering. Compos Sci Technol. 2010;70:1894-1908.

22. Wu ZY, Tang TT, Guo H, et al. In vitro degradability, bioactivity and cell responses to mesoporous magnesium silicate for the induction of bone regeneration. Colloids Surf B Biointerfaces. 2014;120:38-46.

23. He DW, Dong W, Tang SC, et al. Tissue engineering scaffolds of mesoporous magnesium silicate and poly( $\varepsilon$-caprolactone)-poly(ethylene glycol)-poly (ع-caprolactone) composite. J Mater Sci Mater Med. 2014; 25:1415-1424.

24. Fu SZ, Yang LL, Fan JA, et al. In vitro mineralization of hydroxyapatite on electrospun poly (-caprolactone)-poly(ethylene glycol)-poly (-caprolactone) fibrous scaffolds for tissue engineering. Colloids Surf B Biointerfaces. 2013;107:167-173.

25. Lu W, Ji K, Kirkham J. Bone tissue engineering by using a combination of polymer/bioglass composites with human adipose-derived stem cells. Cell Tissue Res. 2014;356:97-107.

26. Zhou YH, Wu CT, Zhang XF, Han PP, Xiao Y. The ionic products from bredigite bioceramics induced cementogenic differentiation of periodontal ligament cells via activation of the Wnt/beta-catenin signalling pathway. J Mater Chem B. 2013;1:3380-3389.

27. Liang SL, Cook WD, Thouas GA. The mechanical characteristics and in vitro biocompatibility of poly(glycerol sebacate)-Bioglass (R) elastomeric composites. Biomaterials. 2010;31:8516-8529.

28. Yazdimamaghani M, Vashaee D, Assefa SH. Macroporous gelatin/ bioactive-glass/nanosilver scaffolds with controlled degradation behavior and antimicrobial activity for bone tissue engineering. J Biomed Nanotechnol. 2014;10:911-931.

29. Wang HN, Li YB, Zuo Y. Biocompatibility and osteogenesis of biomimetic nano-hydroxyapatite/polyamide composite scaffolds for bone tissue engineering. Biomaterials. 2007;28:3338-3348.
International Journal of Nanomedicine

\section{Publish your work in this journal}

The International Journal of Nanomedicine is an international, peerreviewed journal focusing on the application of nanotechnology in diagnostics, therapeutics, and drug delivery systems throughout the biomedical field. This journal is indexed on PubMed Central, MedLine, CAS, SciSearch ${ }^{\circledR}$, Current Contents ${ }^{\circledR} /$ Clinical Medicine,

\section{Dovepress}

Journal Citation Reports/Science Edition, EMBase, Scopus and the Elsevier Bibliographic databases. The manuscript management system is completely online and includes a very quick and fair peer-review system, which is all easy to use. Visit http://www.dovepress.com/ testimonials.php to read real quotes from published authors. 